九州大学学術情報リポジトリ

Kyushu University Institutional Repository

On the Problem of Introducing the Transfer of Products into the Spatial Equilibrium Model of An Imperfectly Competitive Market

Lin, Lily

Department of Agricultural Economics, Faculty of Agriculture, Kyushu University

Kawaguchi, Tsunemasa

Department of Agricultural Economics, Faculty of Agriculture, Kyushu University

https://doi.org/10.5109/24324

出版情報：九州大学大学院農学研究院紀要. 44 (1/2)，pp. 235-248，1999-11. Kyushu University バージョン：

権利関係 : 


\title{
On the Problem of Introducing the Transfer of Products into the Spatial Equilibrium Model of An Imperfectly Competitive Market
}

\author{
Lily Lin and Tsunemasa Kawaguchi \\ Department of Agricultural Economics, Faculty of Agriculture \\ Kyushu University, Fukuoka 812-8581, Japan \\ (Received July 7, 1999 and accepted August 24, 1999)
}

\begin{abstract}
In the previous studies, we discussed the spatial equilibrium model applied in a perfectly competitive market. However, in some cases, the market may be explained in an imperfect compelition model. In a perfectly competitive market, the price difference between any two demand markets is less than or equal to the transportation cost among those markets. But such a situation may not occur in an imperfectly competitive market, that is, the price difference between any two demand markets may be larger than the transportation cost. Then, in such a casc, the transfer of the product would take place among those two markets. In this stirdy, we would like to discuss the problem of introducing transfer into the spatial equilibrium model and apply it to the japanese milk industry.
\end{abstract}

\section{INTRODUCTION}

\section{Price structure in the Japanese milk industry}

It is useful to understand the complicated price structure (Fig. 1) of the Japanese milk industry before we apply the spatial price equilibrium model to it. Dairy price support in Japan was first implemented in 1961. Producer prices for manufacturing milk were supported within a price "band" through intervention by the Livestock Industry

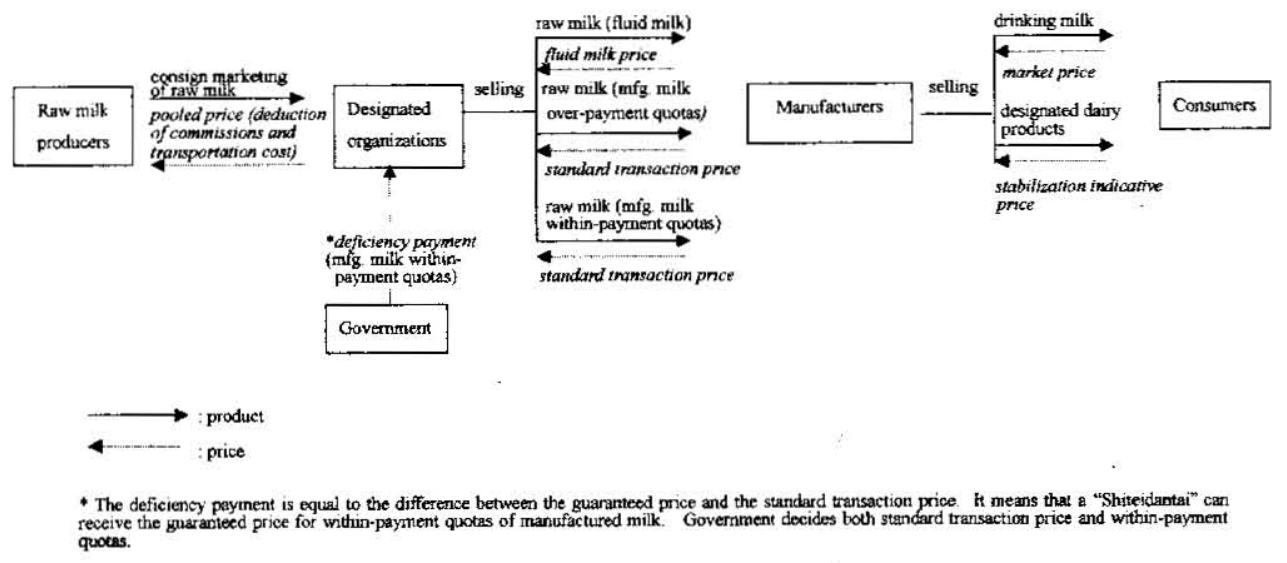

Fig. 1. Structure of deficiency payment system in the Japanese milk industry 


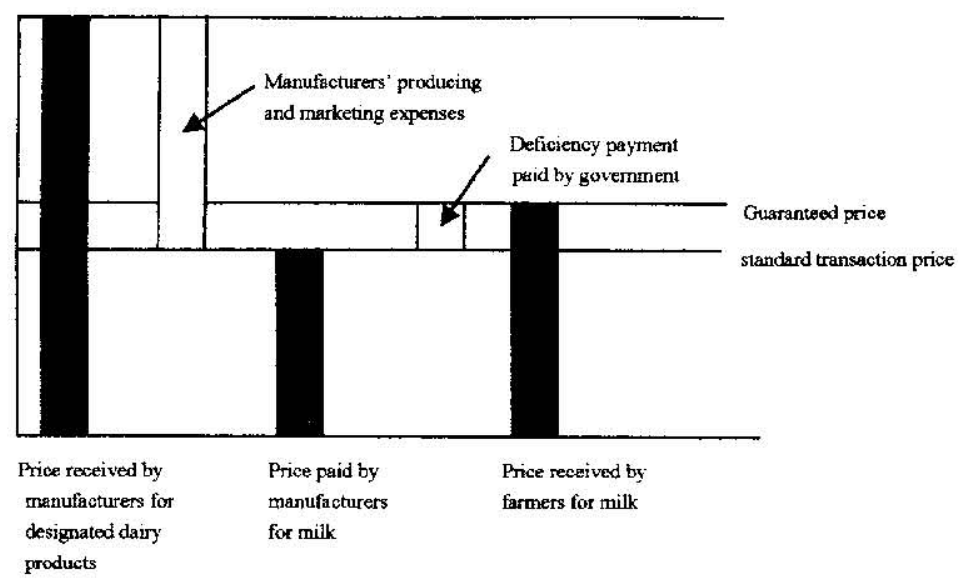

Fig. 2. Price support in the Japanese milk industry

Promotion Council. Thereafter, the dairy price support policy was revised by the Temporary Law on Deficiency Payments for manufacturing milk producers in 1966.

Price support is based on three linked policies: deficiency payments to marufacturing milk producers, market intervention for certain dairy products, and state trading of dairy products. The deficiency payment is the core of the price support program. Farmers receive a deficiency payment equal to the difference between a guaranteed price and a standard transaction price of manufacturing milk. The Japanese government conducts both prices. (Fig. 2)

Payments are made to eligible milk producers' associations for a fixed quantity of milk used for specified milk products. The specified milk products are butter, skimmed milk powder, swcetened condensed whole milk, sweetened condensed skimmed milk, whole milk powder, sweetened milk powder, condensed whole milk, skimuned milk for arimial feed, and natural cheese. The first four products are further classified as "designated milk products".

The guaranteed price is set to maintain the production of raw milk in districts where most of the milk enters the manufacturing sector. Milk production costs in Hokkaido have served as the base for this price in recent years. The standard transaction price is based on the selling price of milk products after deductions are made for average manufacturing and handling costs. The stabilization indicative price is the domestic market price for the designated products.

If the domestic market prices of designated products were not maintained at least at the stabilization indicative price, manufacturers would have no incentive to buy raw milk at the standard transaction price. Intervention purchases of designated products by the Livestock Industry Promotion Council are designed to maintain that incentive.

Intervention is based on deviations from the stabilization indicative prices. The Livestock Industry Promotion Council is expected to purchase designated products when offered by manufacturers or milk producers' associations at prices equal to 90 percent of 
the stabilization indicative prices. There are some conditions when these purchases may not be required. The Council may sell a designated product when its market price is 104 percent of the stabilization indicative price.

\section{The background of this study}

There is not much difference between the quality of fluid milk and that for further processing (hereafter referred to as "manufacturing milk"). However, in most countries, the fluid milk price is higher than the price for manufacturing milk. This is because the policy in each country is usually set up to alleviate the seasonal variation in the price and supply of raw milk.

The total revenue of a raw milk producer is relative to the price discrimination existing between fluid milk and manufacturing milk. Such price discrimination can exist because fluid milk demand has less price elasticity than the demand for manufacturing milk (i.e., an equal percentage of change in both prices results in a smaller percentage of change in the demand quantity for fluid milk). Additionally, the selling quantity of fluid milk is restricted in comparison to manufacturing milk. Therefore, if the fluid milk price is kept higher than that of manufacturing milk, then, even if the same level of total supply is maintained, producers may still be able to increase the total revenue. For this reason, milk producers and sellers try to make fluid milk premiums as large as possible.

It is necessary to prevent not only a conflict of interests among producers, but also the liquidation sale of chcaper manufacturing milk as fluid milk. In order to gain the advantage of selling at and maintaining the premiums, according to Suzuki (1994), the following conditions should be met:

1) Establish regional unitary organizations of milk shipment and sale;

2) Pay dairy farmers at the pooled or blend price (a weighted average price for milk sold in the fluid and manufacturing milk markets); and,

3) Form regulations regarding the prohibition of liquidating manufacturing milk as fluid milk.

To maintain these conditions and keep the production and price of milk stable, most countries' governments intervene in their dairy industry.

In Japan, the Deficiency Payment Law for manufacturing milk was enacted in 1966 to maintain the stability of the dairy market. The contents of this law include the designation of only one legal organization of raw milk producers (Shitei Seinyu Seisansha Dantai, abbreviated as "Shiteidantai") in each prefecture (Tofuken) that can deal with the prefecture's milk supply based on this law. At that time, the production of raw milk was small and most of it was traded within each prefecture. Because of substantial increases in production and the technological improvement of transportation, the marketing of raw milk broadened, crossing prefecture boundaries throughout the country as Table 1 indicates. Furthermore, following the GATT Uruguay Round, the manufacturing milk market in Japan is going to become international.

Under the open market, we have to reform the demand and supply adjustment system of raw milk based on the Deficiency Payment Law. For example, Japanese organizations may have difficulty in maintaining their current degree of market power after dairy trade liberalization under GATT, because decreases in manufacturing milk prices will cause more competition between Hokkaido and the rest of Japan over fluid 
milk marketing. Fluid milk prices may decline sharply if coordination between the two regions collapses. Therefore, Japanese organizations are now seeking a new system to avoid chaos in the fluid milk market after dairy import quotas are replaced by a tariff equivalent.

Milk markets are not perfectly competitive. Price discrimination exists between fluid and manufacturing milk markets, reflecting the market power of designated organizations and processors; (i.e., fluid milk prices or premiums are determined by the degree of competition in the milk market). Therefore, a measure of the degree of market competition should be introduced in the econometric model. For the Japanese milk market, some inperfect competition models have been developed. For example, a two-region model that focuses on competition and coordination between Hokkaido and the "Tofuken" (the rest of Japan) was used to evaluate the effects of reduced Japanese milk price supports. The other one is a national model developed for the evaluation of the effectiveness of generic milk promotion. Kawaguchi and Suzuki $(1993,1994)$ developed a spatial model of the imperfect competition equilibrium for multiple regions.

The problem regarding the reform of the demand and supply adjustment system of raw milk is not unique to Japan, but is also faced by the USA and other countries after the GAT'T Uruguay Round agreement. The new agriculture law for the LSA which was enacted on April 4, 1996 includes: 1) The policy of supporting payment for manufacturing milk will be canceled by degrees over four years; and, 2) The existing system of 33 marketing orders is going to be reduced to 10 to 14 orders. This reformation is a hot topic. Due to a similar situation, the USA's analysis in reform of the demand and supply adjustment system in the raw milk market may apply to our econometric model.

If we look back over our former research process, there are still two fundamental problems to be resolved and presented regarding the improvement of the existing cconometric model. First, we have to consider the possibility of transfer among markets in the imperfect competition model (oligopolistic market). If the price difference is larger than the transportation cost (or transaction cost) between two different local markets, the transfer may occur between those markets. Secondly, a simplification of the division of the whole target area needs to occur such that each local area includes only one designated arganization in the existing model. However, in practice, some local areas cover more than two designtated organizations. The problem is how to amend the existing model to closely represent the real world. We focus our attention on the first problem in this study.

It is hard to analyze the whole structure of this imperfect competition model with the limits of available space. Therefore this study is restricted to the following discussion, assuming the designated organization of the Cournot-Nash type. In other words, producers in each producing region determine their export and production quantities in accordance with the Nash non-cooperative rule: to maximize their profits by assuming that their decisions do not affect those of producers in other producing regions.

\section{DESCRIPTION OF THE EXISTING MODEL}

The current model we are researching is called a Spatial Nash equilibrium model. It incorporates a "dual structure" which describes the behavior of an oligopolistic market 
Table 1. Regional demand and supply of the Japanese raw milk market (1993)

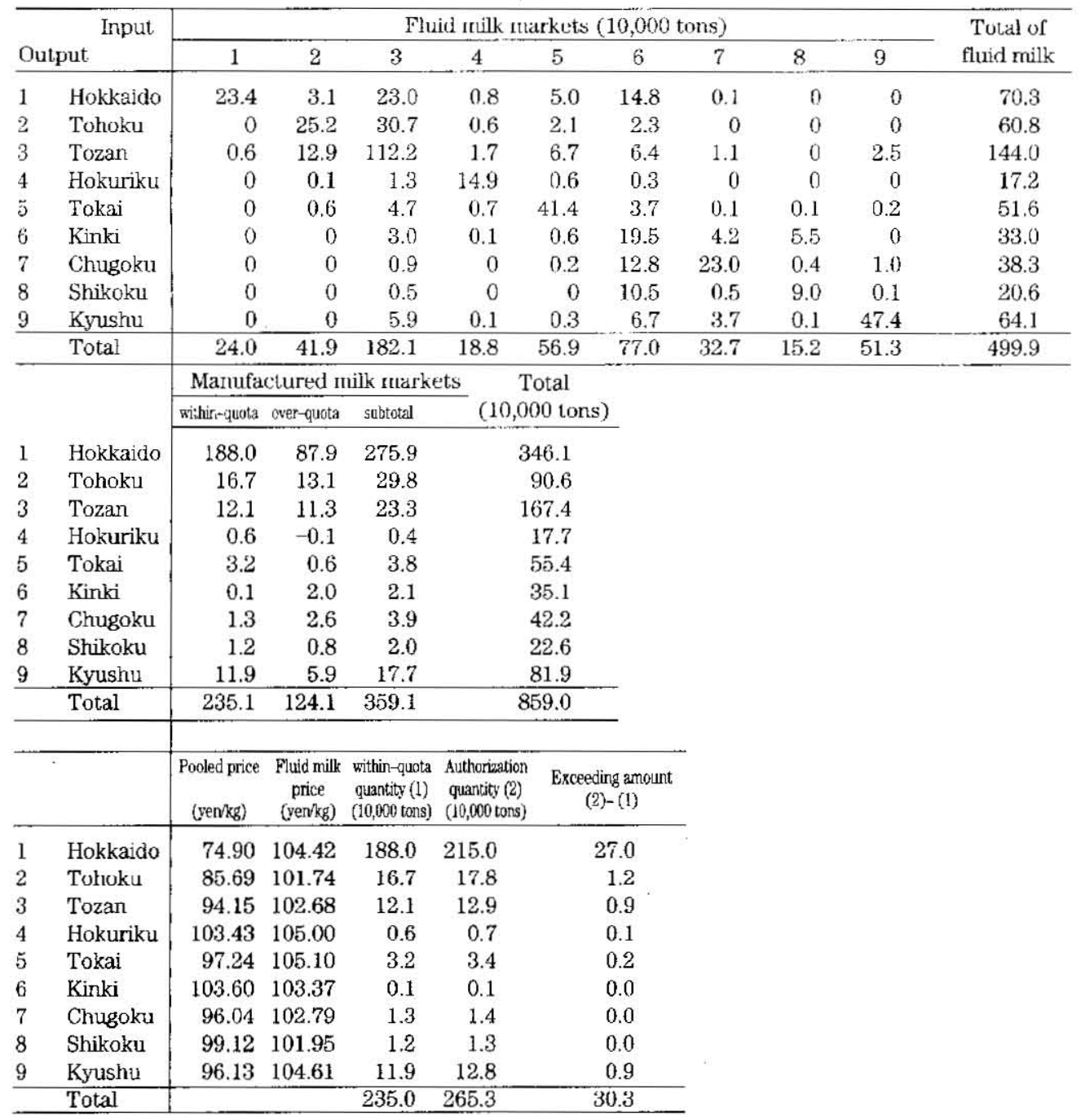

characterized as a Nash non-cooperative game. The details of the model are describcd by Kawaguchi and Suzuki (1994), Kawaguchi et al. (1994). In this study we only present the essentials due to the limited number of pages.

The whole target area of this analysis was divided into 9 regions all over Japan, with the geographical scope of producing region i the same as consuming region i (refer to Table 1). Small-scale raw milk producers connect with the designated organization and then consign raw milk marketing to the organization in each producing region. The designated organizations sell the consigned raw milk as profitably as possible throughout 
Table 2. Linear demand function of fluid milk for each region (1993)

\begin{tabular}{lrrrr}
\hline & & \multicolumn{3}{c}{ Basic Data } \\
\cline { 3 - 5 } Demand functions of fluid milk & $\begin{array}{c}\text { Demand, D } \\
(10,000 \text { ton) }\end{array}$ & $\begin{array}{c}\text { Fluid milk price } \\
\text { PD (yenkg) }\end{array}$ & $\begin{array}{c}\text { Price elasticity } \\
\text { of demand }\end{array}$ \\
\hline $\mathrm{D}(1)=$ & $44.2609-0.1938 \times \mathrm{PD}(1)$ & 24.0287 & 104.42 & -0.842 \\
$\mathrm{D}(2)=$ & $74.1382-0.3170 \times \mathrm{PD}(2)$ & 41.8860 & 101.74 & -0.770 \\
$\mathrm{D}(3)=$ & $293.7660-1.0873 \times \mathrm{PD}(3)$ & 182.1240 & 102.68 & -0.613 \\
$\mathrm{D}(4)=$ & $32.9096-0.1341 \times \mathrm{PD}(4)$ & 18.8270 & 105.00 & -0.748 \\
$\mathrm{D}(5)=$ & $87.6106-0.2927 \times \mathrm{PD}(5)$ & 56.8531 & 105.10 & -0.541 \\
$\mathrm{D}(6)=$ & $137.9956-0.5900 \times \mathrm{PD}(6)$ & 77.0065 & 103.37 & -0.792 \\
$\mathrm{D}(7)=$ & $54.5941-0.2127 \times \mathrm{PD}(7)$ & 32.7303 & 102.79 & -0.668 \\
$\mathrm{D}(8)=$ & $23.4613-0.0814 \times \mathrm{PD}(8)$ & 15.1657 & 101.95 & -0.547 \\
$\mathrm{D}(9)=$ & $95.0161-0.4179 \times \mathrm{PD}(9)$ & 51.3046 & 104.61 & -0.852 \\
\hline
\end{tabular}

Table 3. Linear supply function of raw milk for each region (1993)

\begin{tabular}{|c|c|c|c|c|}
\hline \multirow{2}{*}{\multicolumn{2}{|c|}{ Supply functions of raw milk }} & \multicolumn{3}{|c|}{ Basic Data } \\
\hline & & \multirow{2}{*}{$\begin{array}{c}\text { Supply, S } \\
(10,000 \text { ton }) \\
346.1376\end{array}$} & \multirow{2}{*}{$\begin{array}{c}\text { Pooled price } \\
\mathrm{MP} \text { (yen } / \mathrm{kg}) \\
74.90\end{array}$} & \multirow{2}{*}{$\begin{array}{c}\begin{array}{c}\text { Price elasticity } \\
\text { of supply }\end{array} \\
1.2806\end{array}$} \\
\hline$S(1)=$ & $-97.1262+5.9181 \times \mathrm{MP}(1)$ & & & \\
\hline $\mathrm{S}(2)=$ & $-3.2098+1.0953 \times \mathrm{MP}(2)$ & 90.6463 & 85.69 & 1.0354 \\
\hline$S(3)=$ & $-63.6384+2.4537 \times \mathrm{MP}(3)$ & 167.3814 & 94.15 & 1.3802 \\
\hline$S(4)=$ & $-14.3267+0.3095 \times \mathrm{MP}^{2}(4)$ & 17.6873 & 103.43 & 1.8100 \\
\hline$S(5)=$ & $-45.0904+1.0339 \times \mathrm{MP}(5)$ & 55.4413 & 97.24 & 1.8133 \\
\hline$S(6)=$ & $23.1160+0.1154 \times \operatorname{MP}(6)$ & 35.0721 & 103.60 & 0.3409 \\
\hline$S(7)=$ & $-14.2531+0.5880 \times \mathrm{MP}(7)$ & 42.2190 & 96.04 & 1.3376 \\
\hline$S(8)=$ & $1.7684+0.2100 \times \mathrm{MP}^{3}(8)$ & 22.5848 & 99.12 & 0.9217 \\
\hline$S(9)=$ & $-80.1639+1.6855 \times$ MP (9) & 81.8584 & 96.13 & 1.9793 \\
\hline
\end{tabular}

Japan and decide how to distribute the revenue in advance based on the pooled milk price (calculated by a fixed formula). There is one thing different from the usual oligopolistic firm in this case. The profit does not belong to the designated organization, but should be returned to the members of the cooperative association (producers).

The designated organizations can sell the raw milk either for fluid milk or for manufacturing materials in each consuming region. Moreover, the government pays the designated organization a deficiency payment that is equal to the difference between the guaranteed price and the standard transaction price within the permitted quota. Manufacturers are obligated to buy raw milk at the standard transaction price for milk sold. Fluid milk prices that are determined by negotiation between the manufacturers and designated organizations are variable through the relation of demand and supply. Needless to say, the price may be affected by the degree of competition or cooperation among the designated organizations.

These designated organizations pay the small-scale producers at the prefecture-wide uniform pooled price, then each producer can determine the quantity of raw milk he will 
Tabie 4. Unit transportation cost of raw milk

(Unit: yen / kg)

\begin{tabular}{|c|c|c|c|c|c|c|c|c|c|c|}
\hline & & Hokkaido & Tohoku & Tozan & Hokuriku & Tokai & Kinki & Chugoku & Shikoku & Kyushu \\
\hline & & 1 & 2 & 3 & 4 & 5 & 6 & 7 & 8 & 9 \\
\hline Hokkaido & 1 & 0 & 14.79 & 17.11 & 20.25 & 19.49 & 17.58 & 23.95 & 20.06 & 31.35 \\
\hline Tohoku & 2 & 14.79 & 0 & 8.43 & 11.15 & 15.06 & 17.41 & 22.88 & 19.90 & 29.14 \\
\hline Tozan & 3 & 17.11 & 8.43 & 0 & 9.40 & 8.75 & 11.93 & 17.41 & 14.42 & 23.67 \\
\hline Hokuriku & 4 & 20.25 & 11.50 & 9.40 & 0 & 6.49 & 8.75 & 14.28 & 10.78 & 20.54 \\
\hline Tokai & 5 & 19.49 & 15.06 & 8.75 & 6.49 & 0 & 5.52 & 11.15 & 7.88 & 17.41 \\
\hline Kinki & 6 & 17.58 & 17.41 & 11.93 & 8.75 & 5.52 & 0 & 8.11 & 3.92 & 14.28 \\
\hline Chugoku & 7 & 23.95 & 22.88 & 17.41 & 14.28 & 11.15 & 8.11 & 0 & 6.18 & 8.75 \\
\hline Shikoku & 8 & 20.06 & 19.09 & 14.42 & 10.78 & 7.88 & 3.92 & 6.18 & 0 & 12.62 \\
\hline Kyushu & 9 & 31.35 & 29.14 & 23.67 & 20.54 & 17.41 & 14.28 & 8.75 & 12.62 & 0 \\
\hline
\end{tabular}

Source: Please refer to Suzuki and Kawaguchi (1996), Table 7.

produce. Namely, the small-scale producers are assumed to behave as price-takers. The designated organizations receive a 2 -yen $/ \mathrm{kg}$ commission on sales after the transportation fee is deducted as a cost (as Table 4 indicated). In addition, the designated organizations cannot control the raw milk production and consigned quantity for dairy farmers, which are decided by those farmers themselves and based on the pooled price. Although the federation of designated organizations set up short-run production limitations, there is no production limitation for the long run because of the change in the short-run limitation's self.

The relation between each producing region's production and pooled price, as shown in Table 3, is the region's supply function (the same as the marginal cost function), and the relation between each consuming region's fluid milk demand and its market price, as shown in Table 2 , is their respective demand function. To make the model obvious we still maintain the deficiency payment but ignore the production limitation.

The model incorporates a "dual structure" in which there are oligopolistic designated organizations (consignment sellers or producer marketing boards) and perfectly competitive producers (price-takers) receiving pooled returns. Actually, the raw milk market is an imperfectly competitive market composed of designated organizations and giant dairy manufacturers (i.e. Snow Brand, Meiji, and Morinaga). In addition, there are numerous geographically separated producing regions that make the model complicated. Therefore, we call this model a dual structure imperfect competition spatial equilibrium model.

\section{THE PROBLEM TO BE SOLVED IN THIS STUDY}

Considering the above dual structure imperfect competition spatial equilibrium model, the designated organizations maximize sales revenues for consigned milk, and return the pooled price to milk producers. The problem is how to decide the equilibrium of the consigned milk quantity and the pooled price. We can get the answer by solving the Quadratic Programming Problem (QPP) or Linear Complementary Problem (LCP) (Kawaguchi and Suzuki $(1993,1994)$, Kawaguchi et al. (1994)). In this paper, we do not 
explain the formulations for solutions for both methods.

Because any designated organization can, individually or in coalition with other designated organizations, sell the consigned milk as a price-taker or according to Cournot-Nash behavior, many combinations of marketing behavior for designated organizations can be simulated.

If designated organizations behave as price-takers, and each designated organization maximizes its sales revenues by assuming that its decisions do not affect those of designated organizations in other prefectures, then we can call this case the "dual structure" perfect competition spatial equilibrium model (the solution is shown in Table 5). The amount of milk allocated to the fluid market in the perfect competition solution is substantially higher than the actual amount allocated (see Table 1). This is due to the assumption that agents act as price-takers, which results in the equality of the price-across-markets net for transportation costs, instead of the equality across markets of the "perceived" marginal revenues net for transportation costs. Consequently, fluid milk prices and producer-pooled prices in the perfect competition case are much lower than actual levels. In this case, however, the difference in fluid milk prices across markets is the same as the transaction costs across markets, making profitable intermarket transfers impossible.

If each designated organization acts according to the Nash non-cooperate rule, and each designated organization maximizes its sales revenues by assuming that its decisions

Table 5. Equilibrium solutions under dual-structure of perfectly competitive markets (1993)

\begin{tabular}{|c|c|c|c|c|c|c|c|c|c|c|c|}
\hline \multirow{2}{*}{\multicolumn{2}{|c|}{$\begin{array}{l}\text { Input } \\
\text { Output }\end{array}$}} & \multicolumn{9}{|c|}{ Fluid milk markets $(10,000$ tons) } & \multirow{3}{*}{$\begin{array}{c}\begin{array}{c}\text { Total of } \\
\text { fluid milk }\end{array} \\
137.4\end{array}$} \\
\hline & & \multirow{2}{*}{$\frac{1}{30.9}$} & \multirow{2}{*}{$\frac{2}{0}$} & \multirow{2}{*}{$\begin{array}{c}3 \\
36.7\end{array}$} & \multirow{2}{*}{4} & \multirow{2}{*}{$\begin{array}{c}5 \\
17.6\end{array}$} & \multirow{2}{*}{$\frac{6}{52.2}$} & \multirow{2}{*}{$\frac{7}{0}$} & \multirow{2}{*}{$\frac{8}{0}$} & \multirow{2}{*}{$\frac{9}{0}$} & \\
\hline 1 & Hokkaido & & & & & & & & & & \\
\hline 2 & Tohoku & 0 & 49.6 & 21.4 & 8.5 & 0 & 0 & 0 & 0 & 0 & 79.5 \\
\hline 3 & Tozan & 0 & 0 & 142.3 & 0 & 0 & 0 & 0 & 0 & 0 & 142.3 \\
\hline 4 & Hokuriku & 0 & 0 & 0 & 12.5 & 0 & 0 & 0 & 0 & 0 & 12.5 \\
\hline 5 & Tokai & 0 & 0 & 0 & 0 & 44.1 & 0 & 0 & 0 & 0 & 44.1 \\
\hline 6 & Kinki & 0 & 0 & 0 & 0 & 0 & 32.9 & 0 & 0 & 0 & 32.9 \\
\hline 7 & Chugoku & 0 & 0 & 0 & 0 & 0 & 0 & 36 & 0 & 0 & 36.0 \\
\hline 8 & Shikoku & 0 & 0 & 0 & 0 & 0 & 1.9 & 0 & 16.7 & 0 & 18.7 \\
\hline \multirow[t]{4}{*}{9} & Kyushu & 0 & 0 & 0 & 0 & 0 & 0 & 0 & 0 & 59.5 & 59.5 \\
\hline & \multirow[t]{3}{*}{ Total } & 30.9 & 49.6 & 200.3 & 21.0 & 61.8 & 87.0 & 36.0 & 16.7 & 59.5 & 562.9 \\
\hline & & \multicolumn{4}{|c|}{ Manufactured milk markets } & & \multirow{2}{*}{$\begin{array}{c}\text { Pooled price } \\
\text { (yen/kg) }\end{array}$} & \multirow{2}{*}{\multicolumn{2}{|c|}{$\begin{array}{c}\text { Fluid millk price } \\
\text { (yenkg) }\end{array}$}} & & \\
\hline & & within-ẹuota & over-quota & subtotal & & & & & & & \\
\hline 1 & Hokkaido & 188 & 0 & 188 & & 325.4 & 71.4 & & 8 & & \\
\hline 2 & Tohoku & 0 & 0 & 0 & & 79.5 & 75.5 & & .5 & & \\
\hline 3 & Tozan & 0 & 0 & 0 & & 142.3 & 83.9 & & 9 & & \\
\hline 4 & Hokuriku & 0 & 0 & 0 & & 12.5 & 86.6 & & 6 & & \\
\hline 5 & Tokai & 0 & 0 & 0 & & 44.1 & 86.3 & & 3 & & \\
\hline 6 & Kinki & 0 & 0 & 0 & & 32.9 & 84.4 & & 4 & & \\
\hline 7 & Chugoku & 0 & 0 & 0 & & 36 & 85.5 & & .5 & & \\
\hline 8 & Shikoku & 0 & 0 & 0 & & 18.7 & 80.5 & & .5 & & \\
\hline \multirow[t]{2}{*}{9} & Kyushu & 0 & 0 & 0 & & 59.5 & 82.9 & & .9 & & \\
\hline & Total & 188 & 0 & 188 & & 750.9 & & & & & \\
\hline
\end{tabular}


do not affect those of designated organizations in other prefectures, then we can call this case the "dual structure" Nash imperfect competition spatial equilibrium model (the solution is shown in Table 6). From Table 6, we can see that, in the case of imperfect competition, fluid milk prices are higher and producer pooled prices are a little lower than actual levels. However, in this case, the regional fluid milk and producer pooled prices in this solution are closer to the actual price than the perfectly competitive case. Compared to Table 5, Table 6 is more complicated in the makeup of the fluid milk shipments, but the mutual transactions across regions is an attractive point.

Considering the solutions in Table 6 , we can find that the fluid milk price differences across some markets are larger than the transportation costs (their differences are shown in Table 7). For example, the fluid milk price difference between Tokai (region 5) and Kinki (region 6) is $109.093-102.125=6.968 \mathrm{yen} / \mathrm{kg}$, which is larger than the transportation costs among these two regions of 5.52 yen $/ \mathrm{kg}$. Thus, the transfer from Kinki to Tokai may occur in reality.

We can make an example of this transfer: That is, there is one dairy company and in its Kinki factory it purchases the fluid milk which is transferred to its factory located in Tokai. The milk can be processed and packed there, or in its Kinki factory before shipping.

The result of the transfer decreases the quantity of final fluid milk consumed

Table 6. Fquilibrium solutions under dual-structure of Nash imperfectly competitive markets (1993)

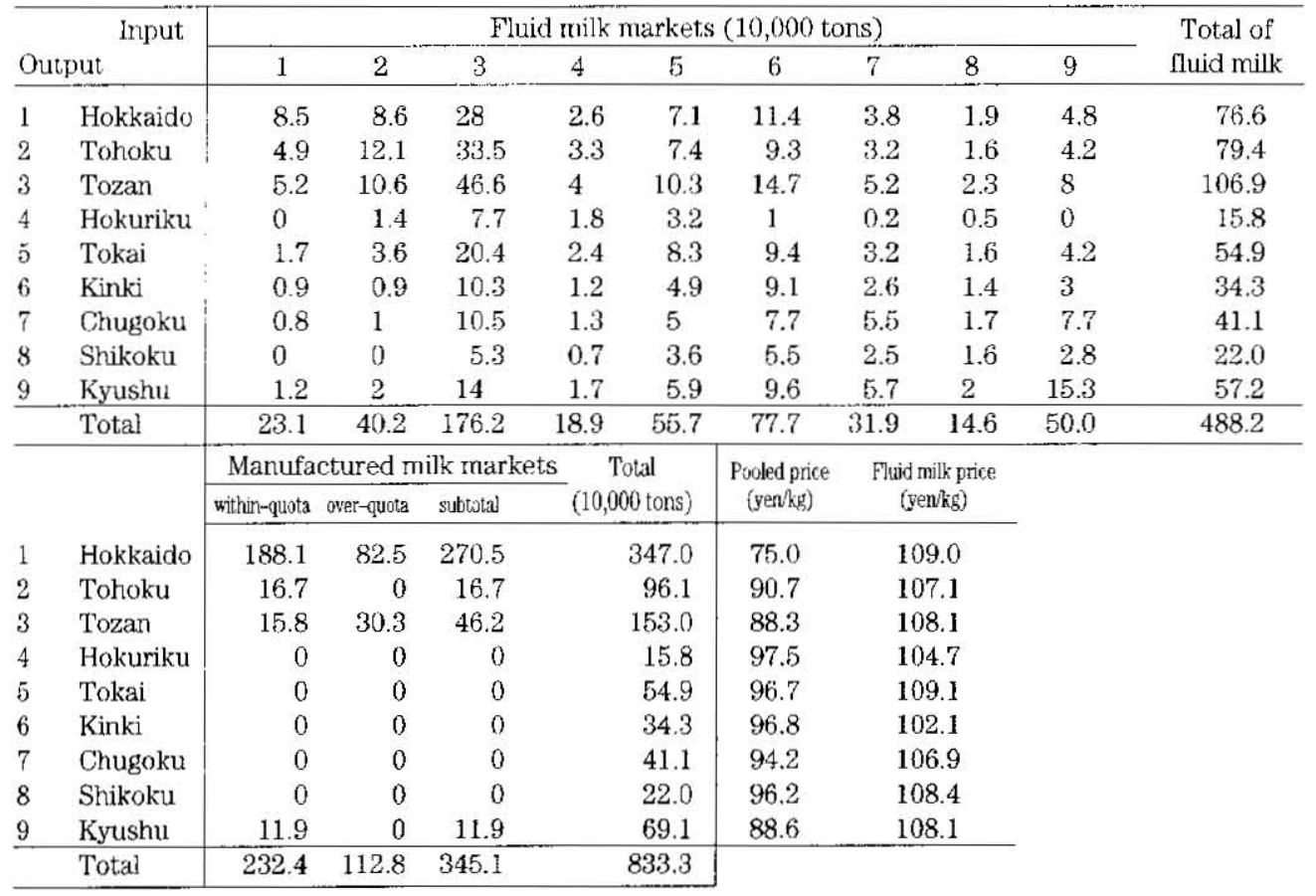


Table 7. Price difference of fluid milk in the case of table table 6 (yen $/ \mathrm{kg}$ )

\begin{tabular}{|c|c|c|c|c|c|c|c|c|c|c|}
\hline & & 1 & 2 & 3 & 4 & 5 & 6 & 7 & 8 & 9 \\
\hline 1 & Hokkaido & 0 & & & & & & & & \\
\hline 2 & Tohoku & 1.916 & 0 & & & & & & & \\
\hline 3 & Tozan & 0.881 & 1.035 & 0 & & & & & & \\
\hline 4 & Hokuriku & 4.306 & 2.390 & 3.425 & 0 & & & & & \\
\hline 5 & Tokai & 0.096 & 2.012 & 0.977 & 4.402 & 0 & & & & \\
\hline 6 & Kinki & 6.872 & 4.956 & 5.991 & 2.566 & $*_{6.968}$ & 0 & & & \\
\hline 7 & Chugoku1 & 2.073 & 0.157 & 1.192 & 2.233 & 2.169 & 4.799 & 0 & & \\
\hline 8 & Shikoku & 0.613 & 1.303 & 0.268 & 3.693 & 0.709 & $* 6.259$ & 1.460 & 0 & \\
\hline 9 & Kyushu & 0.904 & 1.012 & 0.023 & 3.402 & 1.000 & 5.968 & 1.169 & 0.291 & 0 \\
\hline
\end{tabular}

* indicates that the value is larger than the unit transportation cost.

(demanded) in the Kinki region by the amount of the transfer. At the same time, the Kinki fluid milk price increases according to the fluid milk demand function for the Kinki region. Conversely, the final fluid milk consuming quantity for Tokai increases by the amount of transfer, and its price decreases. This kind of situation will lead to a decrease in the difference of these two region's fluid milk prices, and finally to make the price difference equal to the transportation cost between these two regions. The adjustment will be able to reach the new equilibrium condition. However, if we want to obtain the new equilibrium condition by allowing the transfer, we need to consider how to amend the existing model.

\section{INTRODUCING OF THE TRANSFER INTO THE EXISTING MODEL}

The details of our existing model are shown in Kawaguchi and Suzuki (1993, 1994), and Kawaguchi et al. (1994). Here, we only consider the transfer factor in order to amend the existing model.

The original quadratic programming model is conveniently used to generate equilibrium fluid milk prices and quantities in the sales maximization problem. For any pair of region $i$ and $j$ which the transier is allowed, all we have to do is to dud the following new constraints to the QPP:

$\mathrm{PDj}-\mathrm{PDi} \leqq \mathrm{tij}$

$\mathrm{PDj}$ : the fluid milk price in region $\mathbf{j}$

$\mathrm{PDi}$ : the fluid milk price in region $\mathrm{i}$

tij : unit transportation cost between region $\mathrm{i}$ and region $\mathrm{j}$

If we let the transfer quantity from region $i$ to region $j$ equal XT $(i, j)$, the new additional optimal conditions of QPP can be expressed as:

$X T(i, j) \geqq 0$

$\mathrm{XT}(\mathrm{i}, \mathrm{j})[\mathrm{PDj}-\mathrm{PDi}-\mathrm{tij}]=0$

$\mathrm{PDj}-\mathrm{PDi} \leqq$ tij,

and the existing optimal conditions concerning the equilibrium demand of fluid milk in region $j$ and $i$ are revised as follows:

fluid milk demand in region $\mathrm{j}=$ total supply from all regions to region $\mathrm{j}+\mathrm{XT}(\mathrm{i}, \mathrm{j})$ 
fluid milk demand in region $i=$ total supply from all regions to region $i-X T(i, j)$.

Considering the above conditions, a positive XT (i, j) means the transfor occurs and that the fluid milk price difference between two regions is equal to the transportation cost between those regions. On the other hand, the fluid milk price difference cannot be larger than the transportation cost. If transfer occurs, the fluid milk demand in region i decreases by the amount of XT (i. j), and on the other side, the fluid milk demand in region $\mathrm{j}$ increases by the same amount.

The above case is regarding the reform of the demand and supply adjustment system in the Japanese raw milk market. Based on the amended model allowing the transfer, the solution of the "dual structure" Nash imperfect competition spatial equilibrium model is obtained and shown in Table 8 . We can also calculate the fluid milk price difference (shown in Table 9) based on Table 8, figures which are less than or equal to the corresponding transportation cost.

There are two examples of transfer occurring here. The first is 23.731 thousand tons of fluid milk transferred from the Kinki region to the Tokai region. The second one is 13.855 thousand tons of fluid milk moved from the Kinki region to the Shikoku region. Furthermore, from this adjusted equilibrium fluid milk demand, we can get the equilibrium price.

Table 8. Equilibrium solutions under dual-structure of Nash imperfectly competitive markets allowing the transter (1993)

\begin{tabular}{|c|c|c|c|c|c|c|c|c|c|c|c|}
\hline \multirow{2}{*}{\multicolumn{2}{|c|}{ Output ${ }^{\text {Input }}$}} & \multicolumn{9}{|c|}{ Fluid milk markets $(10,000$ torts $)$} & \multirow{3}{*}{$\begin{array}{l}\text { Total of } \\
\text { fluid milk } \\
\frac{76.7}{}\end{array}$} \\
\hline & & \multirow{2}{*}{$\frac{1}{8.5}$} & \multirow{2}{*}{$\frac{2}{8.6}$} & \multirow{2}{*}{$\frac{3}{28}$} & \multirow{2}{*}{$\begin{array}{ll}4 \\
2.6\end{array}$} & \multirow{2}{*}{$\begin{array}{l}5 \\
6.9\end{array}$} & \multirow{2}{*}{$\begin{array}{c}6 \\
11.8\end{array}$} & \multirow{2}{*}{$\frac{7}{3.8}$} & \multirow{2}{*}{$\begin{array}{l}8 \\
1.7\end{array}$} & \multirow{2}{*}{$\frac{9}{4.8}$} & \\
\hline 1 & Hokkaido & & & & & & & & & & \\
\hline 2 & Tohoku & 4.9 & 12.1 & 33.4 & 3.3 & 7.1 & 9.7 & 3.2 & 1.5 & 4.2 & 79.4 \\
\hline 3 & Tozan & 5.2 & 10.6 & 46.6 & 4 & 10 & 15.1 & 5.2 & 2.2 & 8 & 107.0 \\
\hline 4 & Hokuriku & 0 & 1.4 & 7.7 & 1.8 & 3 & 1.4 & 0.2 & 0.3 & 0 & 15.8 \\
\hline 5 & Tokai & 1.7 & 3.6 & 20.3 & 2.4 & 8.1 & 9.8 & 3.2 & 1.5 & 1.2 & 54.8 \\
\hline 6 & Kinki & 0.9 & 0.9 & 10.3 & 1.2 & 4.7 & 9.5 & 2.6 & 1.3 & 3 & 34.4 \\
\hline 7 & Chugoku & 0.8 & 1 & 10.5 & 1.3 & 4.7 & 8 & 5.5 & 1.6 & 7.7 & 41.1 \\
\hline 8 & Shikoku & 0 & 0 & 5.3 & 0.7 & 3.4 & 5.9 & 2.5 & 1.5 & 2.8 & 21.9 \\
\hline \multirow[t]{4}{*}{9} & Kyushu & 1.2 & 2 & 14 & 1.7 & 5.6 & 10 & 5.7 & 1.8 & 15.3 & 57.2 \\
\hline & Total & 23.1 & 40.2 & 176.2 & 18.9 & 53.5 & 81.1 & 31.8 & 13.4 & 49.8 & 488.1 \\
\hline & & \multicolumn{4}{|c|}{ Manufactured milk markets } & & \multirow{2}{*}{$\begin{array}{c}\text { Pooled price } \\
\text { (yen/kg) }\end{array}$} & \multirow{2}{*}{\multicolumn{2}{|c|}{$\begin{array}{l}\text { Fluid milk price } \\
\text { (yen/kg) }\end{array}$}} & & \\
\hline & & within-quota & over-quota & subtotal & & & & & & & \\
\hline 1 & Hokkaido & 188.0 & 82.4 & 270.4 & \multicolumn{2}{|r|}{347.0} & 75.1 & \multicolumn{2}{|c|}{109.0} & & \\
\hline 2 & Tohoku & 16.7 & 0 & 16.7 & \multicolumn{2}{|r|}{96.1} & 90.6 & \multicolumn{2}{|c|}{107.1} & & \\
\hline 3 & Tozan & 15.8 & 30.2 & 46.1 & \multicolumn{2}{|r|}{153.0} & 88.3 & \multicolumn{2}{|c|}{108.1} & & \\
\hline 4 & Hokuriku & 0 & 0 & 0 & \multicolumn{2}{|r|}{15.8} & 97.2 & \multicolumn{2}{|c|}{104.7} & & \\
\hline 5 & Tokai & 0 & 0 & 0 & & 54.8 & 96.6 & \multicolumn{2}{|c|}{108.3} & & \\
\hline 6 & Kinki & 0 & 0 & 0 & & 34.3 & 96.9 & \multicolumn{2}{|c|}{102.8} & & \\
\hline 7 & Chugoku & 0 & 0 & 0 & & 41.1 & 94.1 & \multicolumn{2}{|c|}{107.0} & & \\
\hline 8 & Shikoku & 0 & 0 & 0 & & 21.9 & 96.0 & \multicolumn{2}{|c|}{106.7} & & \\
\hline \multirow[t]{2}{*}{9} & Kyushu & 11.9 & 0 & 11.9 & & 69.1 & 88.5 & \multicolumn{2}{|c|}{108.1} & & \\
\hline & Total & 232.4 & 112.6 & 345.0 & & 833.0 & & & & & \\
\hline
\end{tabular}

$\mathrm{XT}(6,5)=2.3731, \mathrm{XT}(6,8)=1.3855$ 
Table 10 shows the price-quantity relations of the raw milk supply function and the fluid milk demand function hold through the solutions in Table 8 (pooled price, fluid milk price, raw milk supply, fluid milk demand, and fluid milk transfer quantity).

If each designated organization acts according to the Nash non-cooperative rule, and the designated organization of region $i$ increases its shipments to region $j$, the marginal revenue should be equal to $\mathrm{PDj}-(1 / \mathrm{Bj}) \mathrm{Xij}$ based on the Table 2 demand function of fluid milk market $\mathrm{j}(\mathrm{Dj}=\mathrm{Aj}-\mathrm{Bj} \mathrm{PDj})$. In other words, if we increase one unit of shipment, the total revenue increases by one unit of market price which, at the same time, decreases the market price in the amount of $1 / \mathrm{Bj}$. The total shipment quantity is $\mathrm{Xij}$, so the total revenue increase is in the amount of $\mathrm{PDj}-(1 / \mathrm{Bj}) \mathrm{Xij}$ (see Table 11$)$.

Table 9. Price difference of fluid milk in the case of table 8 (yen $/ \mathrm{kg}$ )

\begin{tabular}{|c|c|c|c|c|c|c|c|c|c|c|}
\hline & & 1 & 2 & 3 & 4 & 5 & 6 & 7 & 8 & 9 \\
\hline 1 & Hokkaido & 0 & & & & & & & & \\
\hline 2 & Tohoku & 1.912 & 0 & & & & & & & \\
\hline 3 & Tozan & 0.877 & 1.035 & 0 & & & & & & \\
\hline 4 & Hokuriku & 4.302 & 2.390 & 3.425 & 0 & & & & & \\
\hline 5 & Tokai & 0.711 & 1.201 & 0.166 & 3.591 & 0 & & & & \\
\hline 6 & Kinki & 6.231 & 4.319 & 5.354 & 1.929 & 5.520 & 0 & & & \\
\hline 7 & Chugoku & 2.069 & 0.157 & 1.192 & 2.233 & 1.358 & 4.162 & 0 & & \\
\hline 8 & Shikoku & 2.311 & 0.399 & 1.434 & 1.991 & 1.600 & 3.920 & 0.242 & 0 & \\
\hline 9 & Kyushu & 0.903 & 1.009 & 0.026 & 3.399 & 0.192 & 5.328 & 1.166 & 1.408 & 0 \\
\hline
\end{tabular}

Table 10. Analysis of the result of table 8

\begin{tabular}{|c|c|c|c|c|c|}
\hline \multicolumn{3}{|c|}{ Raw milk supply $(10,000$ tons) } & \multicolumn{3}{|c|}{ Pooled price (yen/kg) } \\
\hline$S(1)=$ & -97.1262 & $+5.9181 \cdot(75.0519)-$ & 347.0384 & $P P(1)=$ & 75.0519 \\
\hline$S(2)=$ & -3.2089 & $-1.0953 \cdot(90.6270)=$ & 96.5490 & $\mathrm{PP}(2)=$ & 90.6270 \\
\hline$S(3)=$ & -63.6384 & $+2.4537 \cdot(88.2975)=$ & 153.0172 & $\mathrm{PP}(3)=$ & 88.2975 \\
\hline$S(4)=$ & -14.3267 & $+0.3095 \cdot(97.1859)=$ & 15.7523 & $\mathrm{PP}^{2}(4)=$ & 97.1859 \\
\hline$S(5)-$ & -45.0904 & $+1.0339 \cdot(96.5999)=$ & 54.7842 & $\mathrm{PP}(5)-$ & 96.5999 \\
\hline $\mathrm{S}(6)=$ & -23.1160 & $+0.1154 \cdot(96.8584)=$ & 34.2935 & $\mathrm{PP}(6)=$ & 96.8584 \\
\hline$S(7)=$ & -14.2531 & $+0.5880 \cdot(94.1309)=$ & 41.0959 & $\mathrm{PP}(7)=$ & 94.1309 \\
\hline$S(8)=$ & 1.7684 & $+0.2100 \cdot(96.0358)=$ & 21.9359 & $P P(8)=$ & 96.0358 \\
\hline \multirow{2}{*}{$S(9)=$} & -80.1639 & $+1.6855 \cdot(88.5424)=$ & 69.0743 & $P^{2} P^{2}(9)=$ & 88.5424 \\
\hline & \multicolumn{2}{|c|}{ Fluid milk demand ( 10,000 tons) } & \multicolumn{3}{|c|}{ Fluid milk price (yen $/ \mathrm{kg}$ ) } \\
\hline $\mathrm{D}(1)=$ & 44.2609 & $-0.1938 \cdot(109.0230)=$ & 23.1322 & $\mathrm{PD}(1)=$ & 109.0230 \\
\hline $\mathrm{D}(2)=$ & 74.1382 & $-0.3170 \cdot(107.1110)=$ & 40.1840 & $P I(2)=$ & 307.1110 \\
\hline$D(3)=$ & 293.7660 & $-1.0873 \cdot(108.1460)=$ & 176.1789 & $\mathrm{PD}(3)=$ & 108.1460 \\
\hline$D(4)=$ & 32.9096 & $-0.1341 \cdot(104.7210)=$ & 18.8665 & $\mathrm{PD}(4)=$ & 104.7210 \\
\hline$D(5)=$ & 87.6106 & $-0.2927 \cdot(108.3120)=$ & 55.9077 & $\mathrm{PD}(5)=$ & 108.3120 \\
\hline$D(6)=$ & 137.9956 & $-0.5900 \cdot(102.7920)=$ & 77.3483 & $\mathrm{PD}(6)=$ & 102.7920 \\
\hline$D(7)=$ & 54.5941 & $-0.2127 \cdot(106.9540)=$ & 31.8450 & $\mathrm{PD}(7)=$ & 106.9540 \\
\hline $\mathrm{D}(8)=$ & 23.4613 & $-0.0814 \cdot(106.7120)=$ & 14.7749 & $\mathrm{PD}(8)=$ & 106.7120 \\
\hline $\mathrm{D}(9)=$ & 95.0161 & $-0.4179 \cdot(108.1200)=$ & 49.8328 & $\mathrm{PD}(9)=$ & 108.1200 \\
\hline
\end{tabular}


Table 11. Marginal revenue decreases of (1/Bj) Xij, accompanying the decrease of fluid milk market price

\begin{tabular}{crrrrrrrrr}
\hline & \multicolumn{1}{c}{ Fluid milk markets } \\
\cline { 2 - 11 } Producing regions & 1 & 2 & \multicolumn{1}{c}{3} & \multicolumn{1}{c}{4} & $\overline{5}$ & 6 & \multicolumn{1}{c}{ (yen/kg) } & \multicolumn{1}{c}{8} & 9 \\
\hline 1 & 43.763 & 27.061 & 25.776 & 19.211 & 23.562 & 19.952 & 17.744 & 21.392 & 11.510 \\
2 & 25.278 & 38.156 & 30.761 & 24.616 & 24.297 & 16.427 & 15.119 & 17.857 & 10.025 \\
3 & 26.653 & 33.421 & $\mathbf{4 2 . 8 8 6}$ & 30.061 & 34.302 & 25.602 & 24.284 & 27.032 & 19.190 \\
4 & 0.000 & 4.297 & 7.802 & 13.057 & 10.158 & 2.378 & 1.011 & 4.268 & 0.000 \\
5 & 8.853 & 11.370 & 18.715 & 17.550 & 27.631 & 16.591 & 15.123 & 18.151 & 10.029 \\
6 & 4.669 & 2.926 & 9.441 & 9.196 & 16.017 & 16.017 & 12.069 & 16.017 & 7.066 \\
7 & 4.025 & 3.183 & 9.688 & 9.393 & 16.114 & 13.634 & 25.906 & 19.484 & 18.322 \\
8 & 0.066 & 0.000 & 4.829 & 5.044 & 11.535 & 9.975 & 11.877 & 17.815 & 6.603 \\
9 & 6.054 & 6.351 & 12.561 & 12.561 & 19.282 & 16.892 & 26.584 & 22.472 & 36.500 \\
\hline
\end{tabular}

If each designated organization maximizes total revenue, then marginal revenue must be equal to each other. This holds true in the example as well. It should be also noted that we can apply the method of this study to introduce transfer of product into other type of spatial equilibrium model of imperfectly competitive market, where any designated organization can sell the consigned milk in coalition with some other designated organizations.

\section{REFERENCES}

Kawaguchi, Tsunemasa and Nobuhiro Suzuki 1993 A Single-Prduct "Dual-Structure" Spatial Imperfect Competition Equilibrium Model and Its Application to the Japanese Milk Market. Sci.Bull. Fac. Agr., Kyushu Univ., 48(1.2): 71-101 (in ,lapanese)

Kawaguchi, Tsunemasa and Nobuhiro Suzuki 1994 An Application of Single--Product "Dual-Structure" Spatial Imperfect Competition Equilibrium Model to the Japanese Milk Market. Journal of Rural Economics, 66-1: 22-34 (in Japanese)

Kawaguchi, Tsunemasa, Suzuki, N. and K. Kobayashi 1994 An Analysis of Milk Marketing Policy in Japan after the Uruguay Round - Choice Betueen Competition and Cooperation -. Association of Agriculture and Forestry Statistics, Tokyo (in Japanese)

Kawaguchi, Tsunemasa 1995 On the Regional Adjustment System of Raw Milk Marketing in Japan Controlled by Realistic Milk Marketing Board of Japanese Stylc - $\Lambda$ djustment by Marginal Reverue Principle Allowing Transfer among Markets - Dairyman, 45(9): 34-36 (in Japanese)

Kawaguchi, Tsunemasa 1995 On the Improvement of the Marginal Revenue Principle for Regional Adjustment System of Raw Milk Marketing - Adjustment by the Fluid Milk Premium Principle Dairyman, $\mathbf{4 5}(10)$ : 28-30 (in Japanese)

Kawaguchi, Tsunemasa and Nobuhiro Suzuki 1996 An Econometric Analysis of the Optimal Strategy for Regional Fluid Milk Marketing. In "1995 Report of Livestock Products Demand Development Research Project", ed. by Livestock Industry Promotion Council (in Japanese), pp. 403-426

Kawaguchi, Tsunemasa 1996 On the Importance of Maintaining Control Power to Check the Linkage of Manufactured and Fluid Milk Price. Dairyman, 46(9): 22-25 (in Japanese)

Sasaki, K. 1970 Spatial Equilibrium in Eastern Japan Pork Industry. J. of Rural Economics, 42-1: 11-19 (in Japanese)

Suzuki, Nobuhiro and D. H. Judson 1991 An Assessment of Deficiency Payments to Milk Producers in Japan. Western Journal of Agricultural Economics, 16(1): 119-131

Suzuki, Nobuhiro and Harry M. Kaiser 1994 Basic Mechanisms of Japanese Dairy Policy and Milk Market Models: A Comparison with United States Dairy Policy. J. Dairy Sci., 77: 1746-1754 
Suzuki, Nobuhiro 1994 Empirical Analyses of Imperfect Competition in Milk Markets. National Research Institute of Agricultural Economics, Tokyo, Japan (in Japanese)

Suzuki, Nobuhiro and T. Kawaguchi 1996 Effects of Increasing Milk Movements from Hokkaido to Other Prefectures and Possibilities of Interregional Marketing Coordination. Quarterly Joumal of Agricultural Economy, 50-3: 37-72 (in Japanese) 